\title{
E-PROC: A experiência da Justiça Federal com o Processo Eletrônico
}

\author{
Quésia Falcão de Dutra ${ }^{1}$ \\ Rafaela Mozzaquattro Machado ${ }^{2}$
}

RESUMO: O presente trabalho versa acerca da implantação do processo eletrônico no Brasil. Seu principal objetivo é a realização de um resgate histórico sobre as formas de procedimentos adotadas até o advento do processo eletrônico, destacando seus aspectos positivos e negativos, bem como analisando a experiência da subseção judiciária da Justiça Federal de Santa Maria na utilização do e-proc.

PALAVRAS-CHAVE: Processo Eletrônico; Justiça Federal.

\section{E-proc: The experience of Federal Justice with the Electronic Process}

ABSTRACT: This article aims to discuss the implantation of the electronic process in Brazil. Its main objective is the accomplishment of a historical rescue on the forms of procedures adopted until the advent of the electronic process, detaching its positive and negative aspects, as well as analyzing the experience of the judiciary sub-section of the Federal Justice of Santa Maria in the use of e-proc.

KEY-WORDS: Federal Justice; Electronic Process.

\section{INTRODUÇÃO}

O processo eletrônico surge como uma alternativa moderna à resolução dos conflitos, objetivando a celeridade na decisão dos mesmos. No que pese a resistência de diversos operadores do Direito, a Lei $n^{\circ} 11.419 / 06$ instituiu a possibilidade de utilização do processo eletrônico, abrindo, assim, as portas do mundo jurídico para a modernidade.

Impende esclarecer o que é o processo eletrônico e em que contexto ele surge no Direito Brasileiro, bem como quais regras impõe para sua operacionalização efetiva. Como objetivo do presente trabalho, tem-se a revisão histórica das formas de procedimento até o advento da legislação supracitada, a análise dos aspectos positivos e negativos do e-proc e a experiência da Justiça Federal em Santa Maria na implantação do novel procedimento.

\section{EVOLUÇÃO HISTÓRICA DO PROCESSO}

Nos primórdios da civilização, a resolução dos conflitos se dava através da autotutela, pela qual cada um dos interessados defendia suas pretensões, não havendo

\footnotetext{
${ }^{1}$ Acadêmica do $9^{\circ}$ Semestre do Curso de Direito da Universidade Federal de Santa Maria, Santa Maria, Rio Grande do Sul, Brasil.

2 Titulação do Autor, Atuação Profissional, Instituição em que é vinculado. E-mail (opcional).

(C) 2008. Departamento de Direito da UFSM. Todos os direitos reservados.
} 
qualquer intervenção estatal. Desse modo, inexistia forma de procedimento organizado, visto que a defesa do interesse ocorria por diversos meios, muitas vezes pelo uso da violência física.

Importante salientar que, neste período, a sociedade era arcaica, possuindo conhecimentos somente acerca dos sistemas da natureza, não havendo qualquer evolução científica ou agrupamento social organizado.

No momento em que a sociedade outorgou ao Estado o poder e o dever de resolução dos seus conflitos, estes passaram a ser solucionados por entes designados pelo próprio Estado.

Inicialmente, o procedimento ocorria de forma predominantemente oral. Desta forma, os atos do processo eram realizados de modo verbal, sem qualquer registro escrito. Neste período, a transcrição em documentos escritos dos relatos de litígios resolvidos era inviável, principalmente pela dificuldade de encontrar locais para inserilos.

Observa-se, a título de exemplificação, que o povo hebreu utilizava procedimentos verbais, os quais eram desenvolvidos diante de árbitros e tinham como base sua Lei Oral. Justifica-se o uso destes procedimentos na sociedade judaica devido ao caráter itinerante do nascedouro de sua nação.

Do mesmo modo, a civilização romana também utilizava procedimentos orais. No período primitivo, os romanos usavam o procedimento das acções, o qual se dividia em duas fases, perante o juiz que fixava a ação da lei e o objeto do litígio; e diante dos árbitros que colhiam provas e prolatavam a sentença. Já no período formulário, as decisões eram proferidas por árbitros, mas efetivadas pelo Estado. Permitia-se a redação de uma fórmula, a qual consistia em um programa de averiguação dos fatos, porém o procedimento se desenvolvia de forma oral. Em Roma, a implantação de um procedimento escrito ocorreu no período da cognitio extraordinária, no qual a função jurisdicional era desenvolvida exclusivamente pelo Estado.

Neste contexto, vale ressaltar que o processo moderno utiliza como base os fundamentos do procedimento romano. Outrossim, necessário considerar o advento da tipografia e das formas de datilografia de documentos na sociedade atual.

O Direito Processual brasileiro, por sua vez, surgiu com base na legislação portuguesa, a qual já usava o procedimento escrito como forma de resolução dos conflitos. 
Tendo em vista o exposto, é possível verificar-se que a evolução do Direito sempre acompanhou as alterações da sociedade, com o escopo de manter sua efetividade. De forma geral, a técnica processual contemporânea preserva o princípio da oralidade, no sentido de que diversos atos do processo são realizados verbalmente. Entretanto, os atos orais são reduzidos a termo e passam a constar nos autos do processo, tendo-se, assim, um procedimento misto.

Ao longo dos séculos, a sociedade caminhou do conhecimento de técnicas rudimentares de sobrevivência para o desenvolvimento de ambientes irreais de comunicação e transmissão de dados virtuais. Desse modo, a utilização de procedimentos escritos em papéis impressos não mais supre as necessidades sociais, considerando a morosidade e burocracia de sua tramitação, bem como os prejuízos ambientais causados pela produção do papel.

Nesta toada, imprescindível se torna o avanço do Direito para adaptar-se às novas tecnologias desenvolvidas pelo homem, inserindo-se neste contexto o processo eletrônico.

\section{O ADVENTO DA LEI Nº 11.419}

Em 19 de dezembro de 2006, foi publicada a Lei $\mathrm{n}^{\circ}$ 11.419, a qual trata da informatização do processo judicial, trazendo modificações ao Código de Processo Civil, especificamente em seus artigos 38, 154, 164, 169, 202, 221, 237, 365, 399, 417, 457 e 556.

Primeiramente, é importante destacar que, conforme o artigo $1^{\circ}$ da supracitada lei, a informatização do processo judicial aplica-se aos processos civil, penal e trabalhista, bem como aos juizados especiais, em qualquer grau de jurisdição.

Tendo sido estabelecido o âmbito de sua incidência, deve-se agora demonstrar o objetivo de sua criação, o qual é de fácil percepção. Através da utilização de um processo completamente informatizado pelo mundo jurídico, por óbvio não se faz mais necessária a utilização de um meio físico. Desta forma, gera-se grande economia, visto que os custos despendidos em um processo eletrônico são sensivelmente menores do que aqueles gastos com a forma física de papel. Ademais, esta inovação traz outra vantagem, qual seja, a celeridade, um dos princípios processuais mais discutidos e almejados atualmente.

(C) 2008. Departamento de Direito da UFSM. Todos os direitos reservados. 
No que toca ao conteúdo da lei em questão, um de seus grandes avanços é permitir a publicação de atos e efetuação de intimações através da Internet, uma vez que seu artigo $4^{\circ}$ fornece aos Tribunais a possibilidade de instituir um Diário de Justiça Eletrônico. Destarte, publicam-se eletronicamente os atos judiciais e administrativos, substituindo-se as outras formas de publicação oficial, ressalvadas algumas exceções e particularidades, como, por exemplo, a de que a data da publicação é fixada como sendo a do primeiro dia útil seguinte ao da disponibilização da informação, sendo o marco inicial do prazo processual o primeiro dia útil após a publicação.

$\mathrm{O}$ artigo $5^{\circ}$, por sua vez, permite que os procuradores sejam intimados por meio eletrônico, tornando-se, mais uma vez, desnecessária a publicação em um órgão oficial. De forma prática, tem-se como realizada a intimação na data em que o intimado consultar eletronicamente o teor da mesma, desde que em dia útil. Não o sendo, esta é considerada efetivada no primeiro dia útil seguinte. Ainda, importa referir que, enviada a intimação, o procurador tem o prazo de dez dias para consultar a informação. Caso não o faça, considerar-se-á intimado no momento do fim do mencionado prazo.

Outro ponto a ser brevemente salientado é a possibilidade de utilização de assinatura digital, prevista no artigo $2^{\circ}$ da Lei 11.419/06. De acordo com a ICP-Brasil ${ }^{3}$ Infra-estrutura de Chaves Públicas Brasileira -, a assinatura digital, também conhecida como assinatura eletrônica ou e-sign, constitui-se: "de um sistema de códigos para identificação e autenticação dos signatários, que é tratado por um software especialmente desenvolvido para essa finalidade".

Este mecanismo tem notável eficácia, permitindo a prática da maioria dos atos processuais por meio eletrônico e, bastando para tanto, apenas um credenciamento no Poder Judiciário em questão, desde que cumpridas as normas por este estabelecidas.

Nesta linha, dentre as suas disposições, é, provavelmente, o artigo $8^{\circ}$ o de maior valor para esta nova concepção do processo. Dada sua relevância, será analisado em tópico próprio.

\section{E-PROC}

Reza o artigo $8^{\circ}$ da Lei no 11.419 que: “Os órgãos do Poder Judiciário poderão desenvolver sistemas eletrônicos de processamento de ações judiciais por meio de autos

\footnotetext{
${ }^{3}$ Extraído do site https://www.icpbrasil.gov.br.

(C) 2008. Departamento de Direito da UFSM. Todos os direitos reservados.
} 
total ou parcialmente digitais, utilizando, preferencialmente, a rede mundial de computadores e acesso por meio de redes internas e externas.

Parágrafo único. Todos os atos processuais do processo eletrônico serão assinados eletronicamente na forma estabelecida nesta Lei”.

Da simples leitura do dispositivo, é possível depreender-se que a implantação de um sistema eletrônico de processamento de ações judiciais é uma mera possibilidade oferecida aos órgãos do Poder Judiciário, cabendo a cada um deles definir a necessidade e/ou vantagem da utilização do mesmo. A razão pela qual se optou pela não obrigatoriedade de adoção deste sistema é a existência de grandes diferenças de estrutura física e orçamental dentre estes órgãos, o que acabaria por impossibilitar a unidade do procedimento. Além disso, cumpre ressaltar que a legislação permite que os autos sejam parcialmente digitais.

Dessa forma, caso um órgão do Poder Judiciário opte por implantar este sistema eletrônico, a ele mesmo incumbirá regulamentá-lo, por certo, dentro de sua competência.

A legislação, ainda, determina que para a realização de atos processuais é necessário o prévio cadastramento do usuário junto ao Poder Judiciário. Embora caiba a cada órgão regulamentar sua forma de cadastramento, faz-se, entretanto, necessária a adequada identificação presencial do usuário.

Cabe consignar que o cadastro confere ao usuário uma assinatura eletrônica, a qual garante a autenticidade da identificação do signatário. Tal autenticidade também pode derivar de uma assinatura digital, baseada em certificado digital emitido por Autoridade Certificadora credenciada. Além disso, o credenciamento possibilita a intimação por meio eletrônico, sendo dispensada a publicação em órgão oficial.

Após o cadastro, os advogados públicos e privados podem apresentar peças processuais, como petição inicial, contestação, recursos e petições genéricas, em formato digital. A distribuição da peça vestibular pode ser feita diretamente pelo procurador da parte, sem qualquer intervenção do cartório judicial, sendo que a autuação do processo ocorre de modo automático.

Importante salientar que a lei prevê a expedição de recibos eletrônicos de protocolo como comprovante da distribuição da petição digital. 
Quanto aos documentos anexados aos processos virtuais, estes podem ser digitalizados, os quais são cópias eletrônicas de documentos físicos, ou eletrônicos, que são confeccionados em meio digital como representação de um fato específico.

Ressalta-se que a lei assegura a origem e o signatário dos documentos anexados aos autos do processo eletrônico, considerando-os, ainda, originais para todos os efeitos legais. Tal disposição possui relação com a força probatória conferida aos documentos que instruem o processo digital. A autenticidade dos documentos, neste sentido, é presumida, só podendo ser ilidida por prova em contrário através da argüição de falsidade do documento original processada de modo digital.

Em conformidade com o artigo 172 do Código de Processo Civil, em um processo físico, em regra, os atos processuais são realizados em dias úteis das seis às vinte horas. Do mesmo modo, de acordo com a regra do artigo 173 do mesmo diploma, não se praticam atos processuais durante as férias e nos feriados. Por fim, consoante o artigo 175 do referido diploma, consideram-se feriados os domingos e dias declarados em lei.

Já em um processo eletrônico, o momento da prática do ato processual ocorre de forma completamente diversa, visto que, na esteira do artigo $3^{\circ}$ da Lei $11.419 / 06$, temse como realizado um ato processual no dia e hora de seu envio ao sistema eletrônico do Poder Judiciário.

Esta novidade representa uma nítida vantagem no tocante ao sistema anterior, porquanto permite aos casuísticos uma maior liberdade, a qual se manifesta de duas maneiras diversas. A primeira é pela comodidade de um envio eletrônico frente à necessidade de comparecer fisicamente ao órgão do Poder Judiciário. A segunda é pelo alargamento dos momentos passíveis de praticarem-se atos processuais, visto que o processo eletrônico está disponível para acesso e envio de petições vinte e quatro horas por dia nos sete dias da semana. Ademais, tendo sido fixado um prazo processual, possui a parte até as 24 horas do dia assinalado para cumprir o que lhe foi determinado, e não mais somente até as 20 horas.

Outra alteração trazida pela lei refere-se à limitação do acesso aos autos. É cediço que um dos princípios basilares do processo civil é o princípio da publicidade, consubstanciado no artigo 155 do Código de Processo Civil, segundo o qual os atos processuais são públicos, excepcionados aqueles que digam respeito a casamento, 
filiação, separação dos cônjuges, conversão deste em divórcio, alimentos e guarda de menores; e aqueles em que o interesse público exigir que corram em segredo de justiça.

Entretanto, o acesso aos autos do processo eletrônico é restrito às partes e ao Ministério Público, violando flagrantemente o princípio da publicidade, o qual, frisa-se, é um dos mais importantes princípios de nossa ordem jurídica. Nesta linha, não há qualquer razão ou motivo de relevo que justifique esta limitação, motivo pelo qual deve ser urgentemente retirada.

Ainda no que cinge ao acesso à justiça, estabelece o $\$ 3^{\circ}$ do artigo 10 da Lei 11.419/06 ser responsabilidade dos órgãos do Poder Judiciário disponibilizar às partes equipamentos que permitam a digitalização de documentos e acesso à rede mundial de computadores para distribuição de peças processuais. Nesta senda, os equipamentos disponibilizados devem estar aptos a propiciar um acesso veloz, adequado e constante.

Outro ponto de relevo da legislação em apreço diz respeito à previsão de indisponibilidade do sistema. Tendo ciência o legislador que os meios de inteligência artificial são falíveis, introduziu dispositivos com o escopo de contornar possíveis erros no sistema.

Neste sentido, havendo indisponibilidade do sistema por motivo técnico, os prazos para prática de determinados atos ficam automaticamente prorrogados para o primeiro dia útil seguinte à resolução da falha.

Além disso, existe a previsão de apresentação em cartório dos documentos cuja digitalização for inviável, tendo em vista o grande volume de dados ou a ilegibilidade das informações neles contidas.

Ademais, o processo eletrônico coaduna-se com as necessidades ambientais dos tempos modernos, pois diminui consideravelmente a utilização de papel no Poder Judiciário.

Como principal elemento positivo do processo virtual, destaca-se a celeridade processual, uma vez que nele inexistem as demoradas cargas de processos aos procuradores das partes e auxiliares da Justiça, bem como não são realizados os morosos procedimentos cartorários para juntada de petições e documentos.

Embora o procedimento digital tenha diversos aspectos positivos, necessário mencionar que os órgãos que o instituírem deverão atuar no sentido de minimizar os efeitos danosos à saúde dos servidores que trabalham diariamente no sistema de processos eletrônicos. Para tanto, práticas como ginástica laboral, reeducação postural e 
utilização de equipamentos ergonômicos deverão ser implementadas nos órgãos referidos.

\section{A EXPERIÊNCIA DA $4^{\mathrm{a}}$ REGIÃO}

O Egrégio Tribunal Regional Federal da $4^{\mathrm{a}}$ Região, reconhecido nacionalmente pelo seu posicionamento vanguardista, instituiu o e-proc (processo eletrônico) por meio da Resolução $n^{\circ}$ 13, de 11 de março de 2004, isto é, dois anos antes da publicação da Lei 11.419/06.

Através da Resolução no 13, o TRF4 autorizou a implantação do processo eletrônico e estabeleceu as normas para seu funcionamento nos Juizados Especiais Federais, Turmas Recursais dos Estados do Paraná, Santa Catarina e Rio Grande do Sul, e na Turma Regional de Uniformização da $4^{\text {a }}$. Região, objetivando alcançar celeridade e economia processual.

Posteriormente, foi editada a Resolução $\mathrm{n}^{\mathrm{o}}$ 75, de 16 de novembro de 2006, a qual determinou que, a partir da data de 31 de março de 2007, deveria ser utilizado o processo eletrônico para todas as ações da competência dos Juizados Especiais Federais da $4^{\mathrm{a}}$ Região, versando sobre matéria de direito ou de fato, inclusive no âmbito das Turmas Recursais e da Turma Regional de Uniformização da $4^{a}$ Região, observadas as disposições da Resolução $n^{\circ}$ 13/04.

Nos dias atuais, o processo eletrônico encontra-se em funcionamento nos Juizados Especiais Federais nas seguintes subseções: a) do Rio Grande do Sul: Bagé, Bento Gonçalves, Cachoeira do Sul, Canoas, Carazinho, Caxias do Sul, Cruz Alta, Erechim, Lajeado, Novo Hamburgo, Passo Fundo, Pelotas, Porto Alegre, Rio Grande, Santa Cruz do Sul, Santa Maria, Santana do Livramento, Santa Rosa, Santiago, Santo Ângelo e Uruguaiana; b) de Santa Catarina: Blumenau, Brusque, Caçador, Chapecó, Concórdia, Criciúma, Florianópolis, Itajaí, Jaraguá do Sul, Joaçaba, Joinville, Lages, Laguna, Mafra, Rio do Sul, São Miguel do Oeste e Tubarão; c) do Paraná: Apucarana, Campo Mourão, Cascavel, Curitiba, Foz do Iguaçu, Francisco Beltrão, Guarapuava, Jacarezinho, Londrina, Maringá, Paranaguá, Paranavaí, Pato Branco, Ponta Grossa, Toledo, Umuarama e União da Vitória.

Especificamente na subseção judiciária de Santa Maria, o processo eletrônico foi implantado em duas varas, quais sejam, $1^{\text {a }}$. Vara Federal e Juizado Especial 
Previdenciário e Vara Federal de Execuções e Juizado Especial Cível. Importante analisar se os pontos positivos e negativos supracitados refletem a realidade da prática forense no procedimento eletrônico.

Na $1^{\text {a }}$. Vara Federal e Juizado Especial Previdenciário de Santa Maria, na qual são ajuizadas cerca de trezentas ações por mês, segundo estatísticas extra-oficiais, estima-se que, nos últimos doze meses, entre a distribuição e a sentença proferida no $e$ proc, houve uma média de cento e oitenta dias de duração. Diante deste dado, verificase que o processo eletrônico permite uma média de tempo inferior ao despendido no procedimento escrito tradicional, proporcionando maior celeridade na resolução dos conflitos.

Deve-se considerar que, entre distribuição e sentença, é realizada toda a instrução do feito, o que inclui perícias e audiências, sendo que o tempo mínimo para percorrer esse iter processual é de cento e quarenta dias.

Destaca-se que, no processo eletrônico, não existe carga dos autos do processo nem intimações demoradas. Além disso, os procuradores que utilizam o e-proc podem elaborar suas peças processuais em qualquer lugar do mundo, possibilitando, assim, maior presteza no desenrolar da lide.

De acordo com as informações prestadas pela Justiça Federal de Santa Maria, o processo poderia ter duração inferior, tendo em vista que, em $80 \%$ dos processos, houve emenda à inicial, atrasando, em média, trinta dias o andamento do feito. Tal estatística deve-se, principalmente, ao desconhecimento do procedimento eletrônico pelos advogados das partes. Cita-se, por exemplo, o fato de que diversas emendas à inicial ocorrem pela impossibilidade de visualização de documentos.

Para evitar que o despreparo com relação ao uso dessa poderosa ferramenta de trabalho atrase o andamento dos processos, a Justiça Federal de Santa Maria já realizou diversos encontros com advogados e peritos, objetivando explicar de modo didático a operacionalização do e-proc.

Outra vantagem ressaltada no uso do e-proc, é a colaboração com a diminuição do impacto ambiental causado pela produção de papel e a redução do espaço físico utilizado para armazenamento e organização de processos físicos.

Ainda, a possibilidade de a Corregedoria analisar processos sem ter que se deslocar até as Varas permite a celeridade na realização de procedimentos 
administrativos e verificação de irregularidades. Para tanto, é necessário que a Corregedoria de cada órgão judiciário organize-se neste sentido.

Como aspecto negativo do e-proc, arrola-se a possibilidade de problemas no sistema que não permitam o acesso aos autos do processo. Contudo, buscam-se soluções que previnam e antevejam as possíveis falhas no sistema. Menciona-se, como exemplo, a gravação em disco rígido dos arquivos constantes em processo a ser analisado durante audiência, com a finalidade de evitar cancelamento de audiências pela inoperância do sistema.

Ressalta-se que o sistema utilizado para acesso do e-proc é inédito e vem sofrendo diversas modificações por uma equipe de técnicos capacitados na área da informática, visando-se, dessa forma, sua adaptação às necessidades de advogados, servidores e auxiliares da Justiça.

Diante disso, tem-se que os aspectos positivos do e-proc são diversos e ultrapassam seus pontos defeituosos. Ademais, as supramencionadas características negativas devem-se a seu caráter de novidade e já estão sendo solucionadas.

Destarte, o caminho tomado pela processualística moderna é a virtualização dos procedimentos. Faz-se necessário, portanto, que os operadores do Direito voltem-se para essa realidade e busquem o aperfeiçoamento de seus conhecimentos, de modo a conseguir operar o sistema e-proc adequadamente. Como assevera conhecido provérbio popular: "Se não pode vencê-los, junte-se a eles".

\section{CONSIDERAÇÕES FINAIS}

Diante do exposto, verifica-se que o e-proc tem tido uma implantação eficaz, alcançando seu objetivo principal, qual seja, a celeridade na prestação jurisdicional.

Em breve, o processo eletrônico será utilizado em larga escala, não mais se apresentado aos operadores do Direito a opção de fechar os olhos e resistir ao progresso.

Não se pode admitir que aqueles que pregam a adequação da sociedade aos ditames do Direito neguem-se a adaptarem-se aos clamores sociais pela utilização da tecnologia em favor da resolução de conflitos.

\section{REFERÊNCIAS BIBLIOGRÁFICAS}

(C) 2008. Departamento de Direito da UFSM. Todos os direitos reservados. 
BRASIL, Código de Processo Civil. 9a edição, São Paulo, Revista dos Tribunais, 2007.

BRASIL, Constituição da República Federativa do Brasil 1988. São Paulo: Revista dos Tribunais, 2007.

FILHO, Demócrito Reinaldo. A informatização do processo judicial. http://jus2.uol.com.br/doutrina/texto.asp?id=9399 (Consultado em 18/06/2008).

Comunicação eletrônica de atos processuais na Lei $n^{0}$ 11.419/06. http://jus2.uol.com.br/doutrina/texto.asp?id=9750\&p=2 (Consultado em 20/06/2008).

LENZA, Pedro. Direito Constitucional Esquematizado. 12a ed. São Paulo: Saraiva, 2008

NERY, Fernando Loschiavo. A virtualização dos processos judiciais (e-proc) e a dispensabilidade de autenticação documental por tabelião. http://jus2.uol.com.br/doutrina/texto.asp?id=4795 (Consultado em 20/06/2008).

SILVA, José Afonso da. Curso de Direito Constitucional Positivo. 24a ed. São Paulo: Malheiros, 2005. 